Supporting Information

\title{
Small-Angle Neutron Scattering Study of Interplay of Attractive and Repulsive Interactions in Nanoparticle-Polymer System
}

\author{
Sugam Kumar ${ }^{\dagger}$, Vinod K. Aswal, ${ }^{\dagger, *}$ and Joachim Kohlbrecher ${ }^{*}$
}

†Solid State Physics Division, Bhabha Atomic Research Centre, Mumbai 400 085, India

Laboratory for Neutron Scattering, Paul Scherrer Institut, CH-5232 PSI Villigen, Switzerland
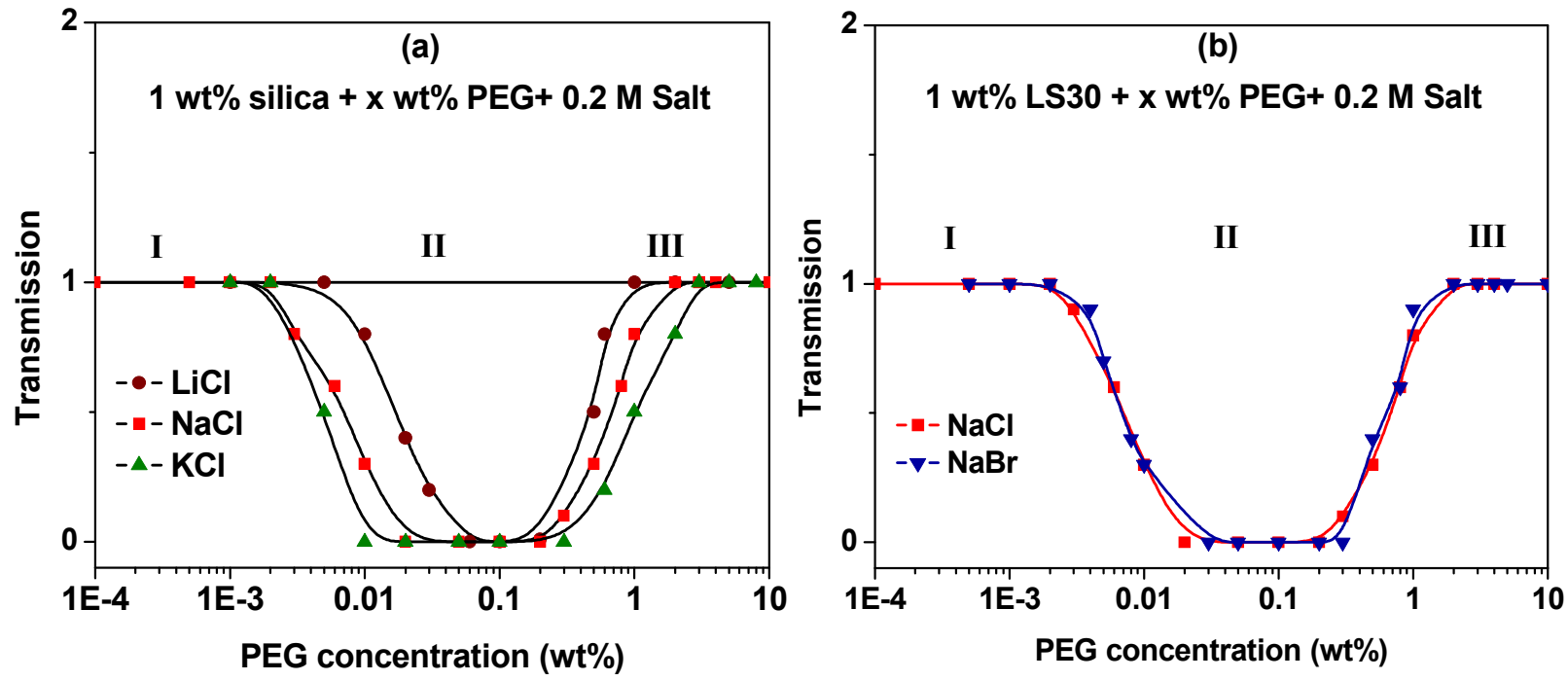

Figure S1. The phase behavior of $1 \mathrm{wt} \%$ LS30 silica nanoparticles with varying PEG polymer concentration in presence of salts with varying (a) counterions $(\mathrm{LiCl}, \mathrm{NaCl}$ and $\mathrm{KCl}$ ) and (b) coions $(\mathrm{NaCl}$ and $\mathrm{NaBr})$. The general features of the phase behavior remain essentially same for all the salts. However, the extent of region of two-phase formation for different counterions follows the order of Hofmeister series i.e. $\mathrm{LiCl}<\mathrm{NaCl}<\mathrm{KCl}$. There is no significant change observed in the phase behavior with varying coions $(\mathrm{NaCl}$ and $\mathrm{NaBr})$. 


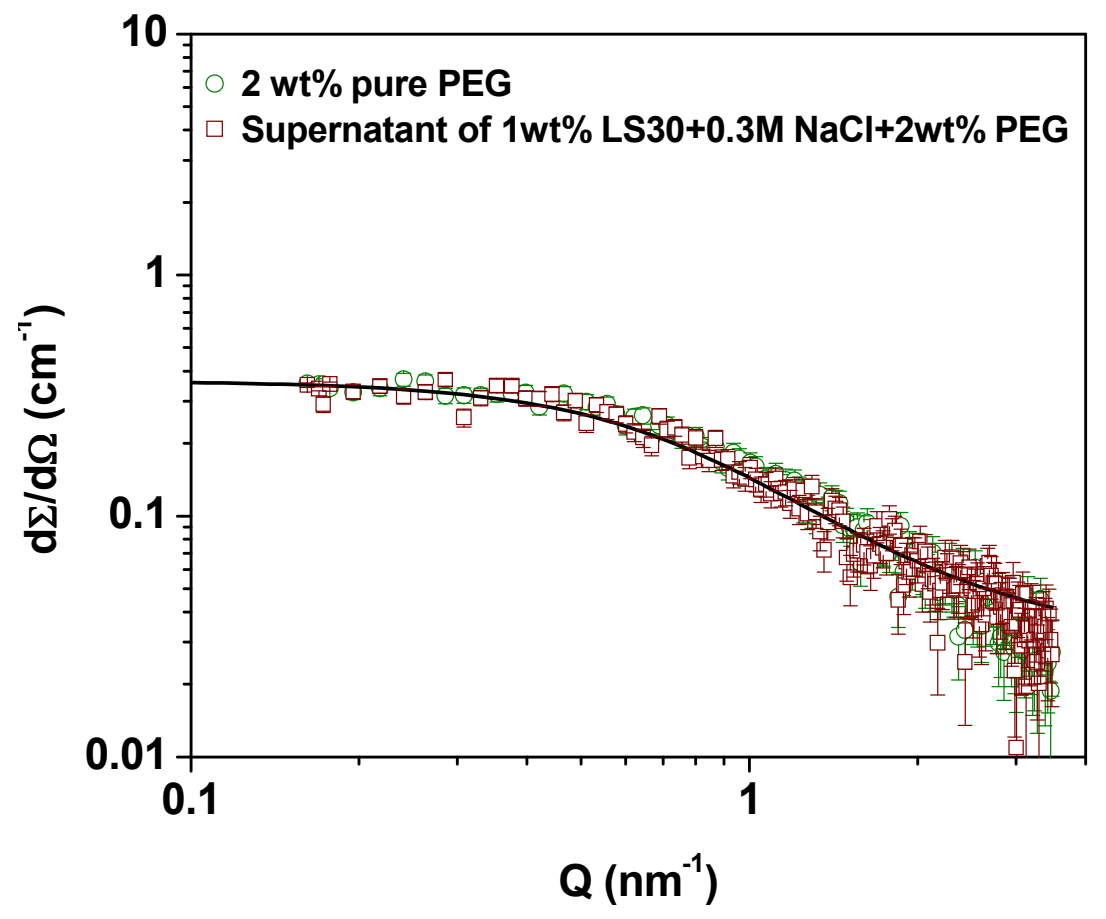

Figure S2. The comparison of SANS data of $2 \mathrm{wt} \%$ pure PEG with supernatant of $1 \mathrm{wt} \% \mathrm{LS} 30$ $+0.3 \mathrm{M} \mathrm{NaCl}+2 \mathrm{wt} \%$ PEG. The supernatant is obtained by centrifuging the system at 10000 RPM for 10 minutes and repeated 3 times. 


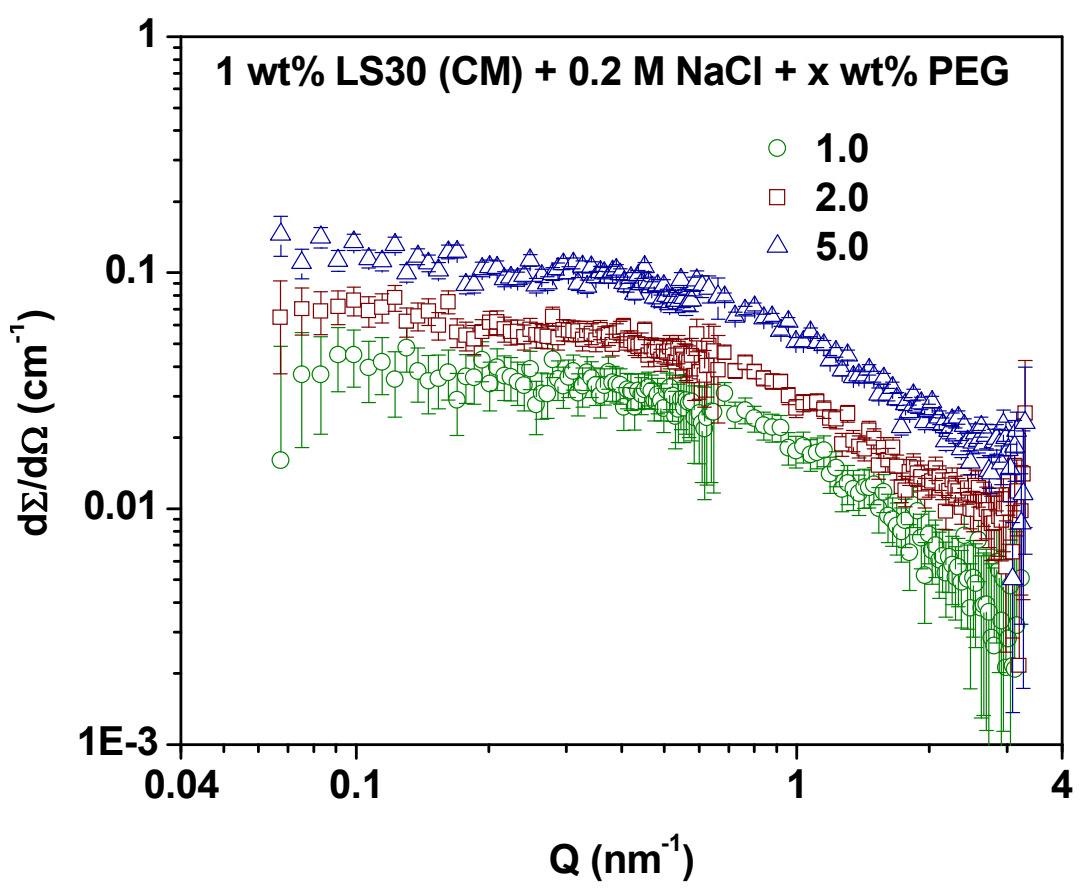

Figure S3. SANS data of $1 \mathrm{wt} \%$ LS30 silica nanoparticles (contrast-matched) with varying PEG polymer concentration in presence of $0.2 \mathrm{M} \mathrm{NaCl}$. The polymer-polymer interaction is not clearly reflected in the data within the polymer concentration range of interest. 